\title{
Cell Surface Interactions of Rhizobium Bacteroids and Other Bacterial Strains with Symbiosomal and Peribacteroid Membrane Components from Pea Nodules
}

\author{
Luis Bolaños, ${ }^{1}$ Miguel Redondo-Nieto, ${ }^{1}$ Rafael Rivilla, ${ }^{1}$ Nicholas J. Brewin, ${ }^{2}$ and IIdefonso Bonilla ${ }^{1}$ \\ ${ }^{1}$ Departamento de Biología, Facultad de Ciencias, Universidad Autónoma de Madrid, 28049-Madrid, Spain; ${ }^{2}$ Department \\ of Genetics, John Innes Centre, Norwich Research Park, Colney Lane, Norwich NR4 7UH, U.K.
}

Submitted 16 June 2003. Accepted 12 October 2003.

\begin{abstract}
Samples of Rhizobium bacteroids isolated from pea nodule symbiosomes reacted positively with a monoclonal antibody recognizing $\mathrm{N}$-linked glycan epitopes on plant glycoproteins associated with the peribacteroid membrane and peribacteroid fluid. An antiserum recognizing the symbiosomal lectin-like glycoprotein PSNLEC-1 also reacted positively. Samples of isolated bacteroids also reacted with an antibody recognizing a glycolipid component of the peribacteroid membrane and plasma membrane. Bacterial cells derived from free-living cultures then were immobilized on nitrocellulose sheets and tested for their ability to associate with components of plant extracts derived from nodule fractionation. A positive antibody-staining reaction indicated that both PSNLEC-1 and membrane glycolipid had become associated with the bacterial surface. A range of rhizobial strains with mutants affecting cell surface polysaccharides all showed similar interactions with PsNLEC-1 and associated plant membranes, with the exception of strain B659 (a deep-rough lipopolysaccharide mutant of Rhizobium leguminosarum). However, the presence of a capsule of extracellular polysaccharide apparently prevented interactions between rhizobial cells and these plant components. The importance of a close association between peribacteroid membranes, PsNLEC-1, and the bacterial surface is discussed in the context of symbiosome development.
\end{abstract}

Rhizobia are soil bacteria that can induce the formation of root nodules in legume plants. Within nodules, rhizobia as endosymbiotic forms can fix atmospheric nitrogen and provide it as ammonia to the host plant cell (Long 1989). During nodule development, the physical and metabolic integration between bacteria and the host cells becomes progressively more intimate. As a result of the exchange of diffusible signal molecules between the legume host and Rhizobium sp., a lipochitin-oligosaccharide (nodulation factor) induces root hair deformation and cortical cell division in the appropriate host legume (Dénarié and Cullimore 1993). Meanwhile, rhizobia make contact with the plant cell surface and invade the plant through a transcellular tunnel termed the infection thread (Brewin 1991). Colonization of nodules with indeterminate apical meristems, such as those developed in Pisum spp., proceeds by growth and ramification of infection threads. Rhizobia in the luminal matrix of these threads continue to grow and divide (Gage et al. 1996) and, thus, they spread from

Corresponding author: L. Bolaños; Telephone: +34 91397 8176; Fax:. +34 91397 8344; E-mail: luis.bolarios@uam.es cell to cell as the infection thread propagates. Eventually, bacteria are released into the intracellular environment from an unwalled infection droplet that extrudes from the thread into the host cytoplasm. Rhizobia from such droplets are engulfed by plasma membrane and come to occupy an organelle-like compartment, termed the symbiosome. Intracellular bacteria, termed bacteroids, proliferate within a plant-derived peribacteroid membrane (PBM) and eventually develop the capacity for nitrogen fixation (Brewin 1991).

Survival of rhizobia in the endophytic environment is possible only if the elicitation of host plant defense responses is suppressed, at least temporarily (Parniske 2000). Several components of the bacterial and host cell interface appear to be involved in determining whether endophytic bacteria adopt a symbiotic rather than a pathogenic relationship (Kannenberg and Brewin 1994). Between the PBM and the bacteroid there is a peribacteroid fluid (PBF) with prelysosomal properties (Mellor 1989). Peribacteroid fluid in pea contains a cysteine protease (Vincent and Brewin 2000; Vincent et al. 2000) and also a group of $\mathrm{N}$-linked glycans recognized by monoclonal antibody MAC254. The most abundant of these is a nodulespecific lectin-like glycoprotein termed Ps-NLEC-1 (Kardailsky et al. 1996), which exists as three isoforms with different electrophoretic mobility (Dahiya el al. 1997). Isoforms 1A and $1 \mathrm{~B}$ have a symbiosomal location but isoform $1 \mathrm{C}$ is absent from the symbiosomal fraction and apparently is associated with nodule supernatant and cytoplasmic membrane fractions. Although the role of these lectin-like glycoproteins is still unclear, observations made in the symbiotically defective pea line Sprint-2 Fix (Brewin et al. 1995; Sherrier et al. 1997), and in boron-deficient pea nodules (Bolaños et al. 2001) suggest that PsNLEC-1 is implicated in symbiosome maturation. Nodules of Sprint-2 Fix (sym31) express only the isoform of PsNLEC-1 that is absent from symbiosomes (Dahiya et al. 1998), and bacteroid development apparently is arrested at a juvenile stage (Sherrier et al. 1997; Tikhonovich et al. 1995). Similarly, under boron deficiency, bacteroids apparently are arrested at a juvenile stage of development and PsNLEC-1 glycoprotein is abnormally glycosylated and targeted, being absent from the symbiosome compartment (Bolaños et al. 2001).

The process of endocytosis marks a transition from the extracellular to the intracellular environment, which probably is driven by a close interaction between rhizobial cells and the surface of the plasma membrane (Robertson and Lyttleton 1984). The plasma membrane and the peribacteroid membrane carry a glycocalyx composed of glycolipids and glycoproteins, which have been partially characterized using monoclonal antibodies (Perotto et al. 1991). The function of this glycocalyx 
is still unknown, but some reports have postulated that it may involve some kind of physical interactions with the plant cell wall (Knox et al. 1991). Similarly, the role of the PBM glycocalyx during symbiosis could involve a physical interaction with the cell surface of Rhizobium spp. Previous studies with isolated plant and bacterial membrane components (Bradley et al. 1986) provided evidence for in vitro binding of the outer membrane of bacteroids with fragments of the peribacteroid membrane. These results suggested that physical contact between bacterial surfaces and plant cell membranes could be a factor for the correct establishment of the symbiosis. Furthermore, during symbiosome maturation, a gradual differentiation of the PBM takes place, resulting in structural (Miao et al. 1992; Perotto et al. 1995) and functional (Day and Udvardi 1993) differentiation of PBM relative to the plasma membrane.

It is probable that Rhizobium spp.-plant cell surface interactions are involved in host cell invasion and symbiosome development. On the bacterial side, cell surface polysaccharides apparently are involved in the establishment of the symbiosis (Ampe et al 2003; Fraysse et al. 2003). Extracellular polysaccharide (EPS) production seems to be important for the initiation of infection threads and the progression of bacteria within them (Cheng and Walker 1998). Rhizobium spp. lipopolysaccharide (LPS) apparently plays an important role during the stages of cell-to-cell propagation and invasion (Perotto et al. 1994) and during bacteroid differentiation (Kannenberg and Carlson 2001). On the plant side, physical interactions with bacteria could be mediated by the PBM glycocalyx or by glycoproteins from the PBF (Bradley et al. 1986). Therefore, the aim of this study was to investigate possible interactions between the cell surface of rhizobial strains and components of PBM or PBF derived from pea nodule symbiosomes.

\section{RESULTS}

\section{Occurrence of peribacteroid fluid and}

membrane antigens associated to the bacteroid cell surface.

In order to identify plant-derived components associated with bacterial surfaces, bacteroids were isolated by differential centrifugation from pea nodules. These bacteroids samples were solubilized, fractionated by sodium dodecyl sulfatepolyacrylamide gel electrophoresis (SDS-PAGE), electroblotted to nitrocellulose sheets, and then immunostained with antibodies (Table 1) recognizing plant-derived components. MAC 254 (anti N-linked glycans in peribacteroid fluid and membrane glycoproteins) recognized several bands that were associated with the bacteroid-enriched fraction isolated from pea nodules (Fig. 1A). This included a band of approximately $30 \mathrm{kDa}$, which corresponds to the relative molecular weight of PsNLEC-1A (Dahiya et al. 1997).Moreover, a band with a relative molecular weight of approximately $14 \mathrm{kDa}$ was recognized by MAC 206 antibody, indicating that a PBMglycolipid also was associated with the bacteroid extracts (Fig. 1B). Conversely, MAC 207, another antibody that reacts with plasma membrane and PBM-glycoprotein epitopes, did not label sucrose-purified bacteroids (Fig. 1C). MAC 57 antibody (which recognizes LPS of the symbiotic bacterium $R$. leguminosarum 3841) was used as control for loading of the bacteroid samples (Fig. 1D). These results provide evidence for a physical interaction between the cell surface of nodulederived Rhizobium bacteroids and plant-derived components of the peribacteroid fluid and peribacteroid membrane.

\section{In vitro interaction}

\section{between nodule fluid fractions and rhizobial strains.}

The possible interaction between plant-derived glycoproteins and rhizobial cells then was tested in vitro by using freeliving cultures of $R$. leguminosarum 3841 and extracts corresponding to high-speed supernatant fractions derived from pea nodule homogenates. These samples contained all three isoforms of the nodule lectin-like glycoprotein PSNLEC1, namely PsNLEC-1A and $-1 \mathrm{~B}$, derived from symbiosomes, and PsNLEC-1C, the cytoplasmic isoform. Free-living bacteria and nodule supernatant fluid were mixed, and binding activity of PsNLEC-1 to the bacterial cell surface was measured after centrifugation of the incubation mixture followed by SDS-PAGE and electroblotting (Fig. 2A). Staining of the pelleted mixture of strain 3841 cells (Fig. 2A, lane 1) indicated that several components recognized by R76 (a monospecific anti-PsNLEC-1 antiserum) were able to interact physically with the surface of Rhizobium cells derived from free-living culture. These included two bands of 30 and 27

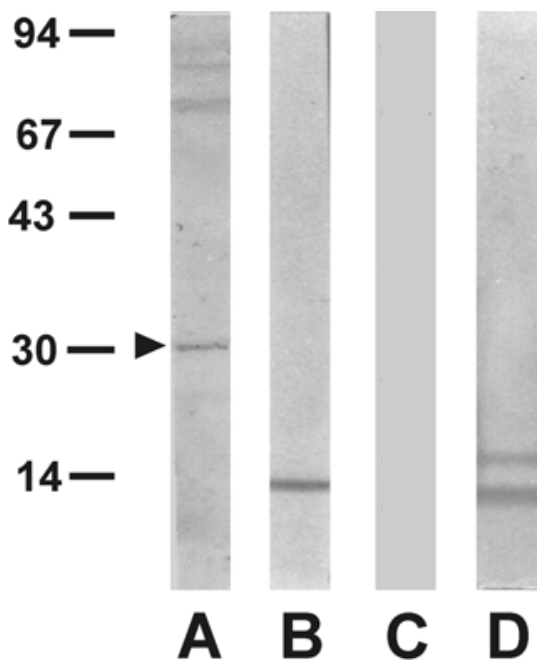

Fig. 1. Co-sedimentation of plant-derived symbiosome components with samples of sucrose-purified bacteroids derived from pea nodules harboring Rhizobium leguminosarum 3841 harvested 3 weeks post infection. Bacteroid samples were subjected to sodium dodecyl sulfatepolyacrylamide gel electrophoresis, blotted on nitrocellulose sheets, and immunostained with monoclonal antibodies. A, MAC 254, recognizing Nglycan epitopes associated with plant glycoproteins in symbiosomes (arrowhead shows a band with similar mobility to PsNLEC-1A); B, MAC 206, recognizing plant glycolipids associated with peribacteroid and plasma membranes; C, MAC 207, recognizing plant arabinogalactan proteins associated with the peribacteroid and plasma membranes; and $\mathbf{D}$, MAC 57, recognizing epitopes on the O-oligosaccharide chain of 3841 lipopolysaccharide from the loaded bacterial samples.

Table 1. Monoclonal antibodies and antisera used in this study

\begin{tabular}{lll}
\hline Designation & \multicolumn{1}{c}{ Antigen recognized } & Reference \\
\hline MAC 254 & Carbohydrate epitope of peribacteroid fluid and membrane glycoproteins & Perotto et al. 1991 \\
MAC 206 & Carbohydrate epitope of peribacteroid and plasma membrane glycolipid & Perotto et al. 1991 \\
MAC 207 & Carbohydrate epitope of peribacteroid and plasma membrane glycoproteins & Perotto et al. 1991 \\
MAC 57 & Lipopolysaccharide (LPS)-1 (O-antigen) of Rhizobium leguminosarum 3841 and B556 & Brewin et al. 1986; Sindhu et al. 1990 \\
R76 & PsNLEC-1 polypeptide & Dahiya et al. 1997 \\
JIM 21 & LPS-1 (O-antigen) of $R$. leguminosarum B556 & Sindhu et al. 1990 \\
\hline
\end{tabular}


$\mathrm{kDa}$ that apparently corresponded to PsNLEC-1A and $-1 \mathrm{~B}$ isoforms. By contrast, the fast-migrating PsNLEC-1C band appeared only in the remaining supernatant fraction (Fig. 2A, lane 2). Pellets of incubations of nodule fluid fractions and agarose beads (Fig. 2A, lane 3) or pellets of 3841 cells alone (Fig. 2A, lane 4) were introduced as negative controls. Because MAC 254 recognizes N-linked glycan epitopes on PsNLEC-1A and -1B that were absent from isoform -1C, replicate blots were stained using this particular monoclonal antibody (Fig. 2B). Lane 1 shows that bands corresponding to PsNLEC-1A and -1B isoforms were detected in the pelleted mixture of Rhizobium cells following treatment with nodule fluid, confirming the results with R76.

Although a negative control using agarose beads instead of 3841 cells was included (Fig. 2A and B, lane 3), to eliminate the possibility that the observed immunostaining with $\mathrm{R} 76$ and MAC 254 (Fig. 2A and B, lane 2) corresponded to cosedimentation of PBF- or PBM-glycoproteins with unattached bacterial cells, a second kind of experiment was designed to avoid the centrifugation step. Aliquots of 3841 cells were washed with Tris-buffered saline buffer (TBS; $50 \mathrm{mM}$ Tris$\mathrm{HCl}, \mathrm{pH} 7.4,200 \mathrm{mM} \mathrm{NaCl}$ ), immobilized on nitrocellulose sheets, and then incubated with nodule fluid. Nitrocellulose sheets were probed with R76 (Fig. 3) or MAC 254 (data not shown). The staining in Figure $3 \mathrm{~A}$ indicates binding of PsNLEC-1 antigens to immobilized bacteria. Replicated immunoblot sheets were probed with MAC 57 as a control for loading of 3841 cells (Fig. 3B), and with MAC 206 to check for general membrane contamination of the bacterial pellet (Fig. 3C). A replicate of the sample dotted in Figure 3A was solubilized in Laemmli buffer and labeled with R76 after SDSPAGE and electroblotting (Fig. 3E). Again, bands including PsNLEC-1A and -1B (Fig. 3E, arrows) but not PsNLEC-1C were positively stained. These results provide further evidence for a binding interaction between PsNLEC-1 (or a symbiosomal component associated with PsNLEC-1) with a component of the Rhizobium cell surface.

In order to investigate the specificity of the interaction between the PSNLEC-associated plant component and the bacterial cell surface, the binding assay was repeated with a number of other bacterial strains. Following incubation with nodule supernatant material, $R$. leguminosarum strain B551 (a mutant defective in production of EPS and then lacking an EPS capsule) gave positive labeling with antiserum R76. So did other rhizobial strains (Sinorhizobium meliloti EFB1 and 2011) and immobilized cells of Escherichia coli DH5 $\alpha$ (Fig. 4). The only strain that was observed to be negative in these binding experiments was $R$. leguminosarum strain B659, a derivative of strain 3841 with a profound defect in LPS assembly and lacking the O-oligosaccharide side chain (Lucas et al. 1996). A replicate sheet of immobilized bacteria was probed with R76 as a negative control (data not shown). These results suggest that the presence of an $\mathrm{O}$-antigen side chain is important for the interaction.

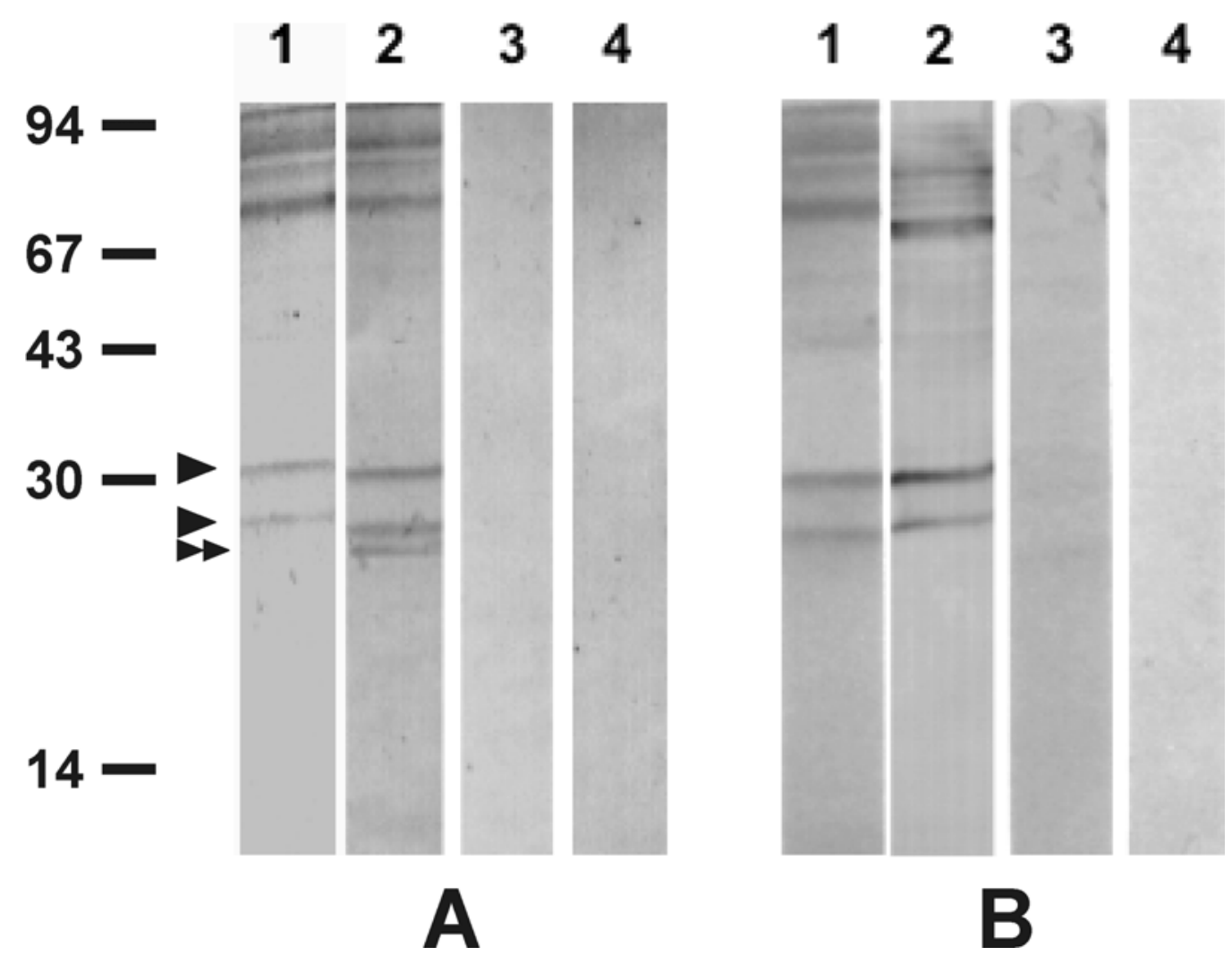

Fig. 2. Co-sedimentation of plant-derived symbiosome components derived from pea nodules with samples of free-living bacterial cells. Bacterial suspensions of strain 3841 were washed in Tris-buffered saline (TBS), and aliquots $(10 \mu \mathrm{l})$ were incubated $\left(1 \mathrm{~h}\right.$ at $\left.4^{\circ} \mathrm{C}\right)$ with aliquots $(50 \mu \mathrm{l})$ of a cytoplasmic supernatant fraction derived from pea nodule homogenates. After incubation and centrifugation, resuspended pellets and supernatants were boiled for 10 min in Laemmli buffer. Solubilized material was separated by sodium dodecyl sulfate-polyacrylamide gel electrophoresis, electroblotted to nitrocellulose, and probed A, on R76 antiserum to detect lectin-like PsNLEC-1 glycoprotein or B, with MAC 254 antibody to identify N-linked glycan epitopes on plant glycoproteins. Lane 1: pellets from mixtures of 3841 cells with nodule cytoplasmic fractions; lane 2: supernatants from mixtures of nodule cytoplasmic fluid and 3841 cells; lane 3: pellets from mixture of nodule cytoplasmic fluid fractions and agarose beads to show that positive staining is not due to coprecipitation of proteins; lane 4: pellets from 3841 cells alone as a negative control for staining. Arrowheads highlight symbiosomal PsNLEC-1A and -1B isoforms; double arrowhead indicates isoform PsNLEC-1C associated with nodule supernatant and cytoplasmic membrane fractions. 


\section{In vitro interaction}

between nodule membrane fractions and rhizobial strains.

Given that an epitope recognized by MAC 206 remained in the bacteroid fraction of nodules after sucrose purification (Fig. 1), potential interactions of PBM and the rhizobial cells were investigated in vitro. TBS-washed bacteria (strain B556 derived from free-living culture) were immobilized on nitrocellulose sheets and incubated with PBM fractions obtained from pea nodules that had been inoculated with Rhizobium strain 3841 (Fig. 5). As expected, the PBM fractions carried epitopes reacting with MAC 57, the LPS antigen characteristic of strain 3841, because bacterial debris was an obvious contaminant of the PBM preparations. To avoid the use of MAC 57 antibody in the analysis, the test strain used in these binding studies was a freeliving culture of $R$. leguminosarum B556, which could be detected by JIM 21, whereas strain 3841 LPS (present in the PBM fractions) cannot be recognized by JIM 21 antibody. In two preliminary control experiments (Fig 5A and B), it was shown that samples of PBM obtained from nodules and immobilized on nitrocellulose reacted positively with MAC 206 (Fig. 5A) but negatively with JIM 21 (Fig. 5B), whereas immobilized B556 cells were recognized by JIM 21 (Fig. 5B) but not by MAC 206 antibody (Fig. 5A). However, when nitrocellulose sheets harboring immobilized PBM samples were incubated with suspensions of B556 cells and then probed with JIM 21 antibody, there was evidence for association of B556 LPS antigen with the immobilized PBM sample (Fig. 5C). These results provide further evidence of a binding activity involving PBM and the Rhizobium cell surface.

\section{Effects of the EPS capsule on nodule-derived fractions and rhizobial cell surface interactions.}

We showed earlier that interactions between the bacterial cell surface and plant membrane or PBF were not affected by the ability to produce extracellular polysaccharide because

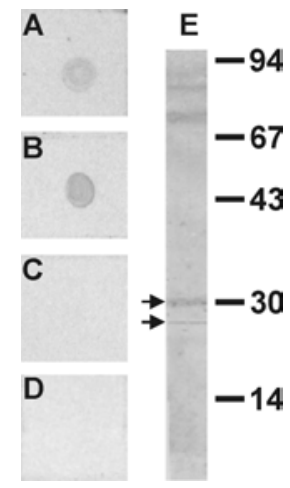

Fig. 3. Binding of the lectin-like glycoprotein PsNLEC-1 from nodule cytoplasmic fluid (R76 antigen) to surface components from Rhizobium leguminosarum 3841 cells that had been immobilized on nitrocellulose sheets. Bacterial cells from free-living culture were washed in Trisbuffered saline (TBS) and aliquots $(1 \mu \mathrm{l})$ were dotted on nitrocellulose sheets and blocked with bovine serum albumin (5\% bovine serum albumin in TBS). Blocked sheets were incubated with cytoplasmic fluid derived from nodule fractions. Following further washing with TBS, the sheets were immunostained with R76 antiserum (A) to reveal the presence of attached antigen corresponding to PsNLEC-1. Replicate sheets were probed with anti-lipopolysaccharide antibody MAC 57 (B) as a control for loading of 3841 cells, or with MAC 206 (C) to confirm the absence of attached plant-derived membrane as a possible contaminant in the sample of nodule cytoplasmic fluid. As a further negative control (D), an immobilized bacterial sample was probed with R76, but without prior incubation with the nodule cytoplasmic fraction. In "E", a replicate of the dot from sample "A" was solubilized in Laemmli buffer separated by sodium dodecyl sulfatepolyacrylamide gel electrophoresis, electroblotted to nitrocellulose, and probed with R76 to reveal the presence of PsNLEC-1 bands (arrows highlight PsNLEC-1A and PsNLEC-1B isoforms). both wild-type and the EPS-defective mutant strains bound to plant components (Fig. 4). However, in those tests, most of the bacterial capsule, including the EPS, would have been removed from bacterial cell surfaces because the bacteria had been washed in TBS. In order to examine the characteristics of bacterial cells with stabilized capsules of EPS, R. leguminosarum strains B556 (wild type) and B551 (EPS-defective derivative blocked in EPS production) were cultured as colonies growing on the surface of nitrocellulose sheets that had been deposited on the surface of tryptone-yeast extract (TY) agar plates. Therefore, the EPS capsule was immobilized on nitrocellulose at the time of colony growth so that is was resistant to TBS washing. Sheets were incubated gently with nodule fluid fractions followed by probing with R76 antiserum for PsNLEC-1 attachment activity (Fig. 6A), with PBM fractions followed by MAC 206 staining (Fig. 6B), or with JIM21 (anti-B556 and anti-B551 LPS antibody), as a control (Fig. 6C). The accessibility of the bacterial surface for binding to PsNLEC-1 and to PBM fractions was very much reduced in the wild-type strain B556 compared with the mutant strain B551 which lacks an EPS capsule (Fig.

\section{B659 B551 EFB1 2011 DH5 $\alpha$}

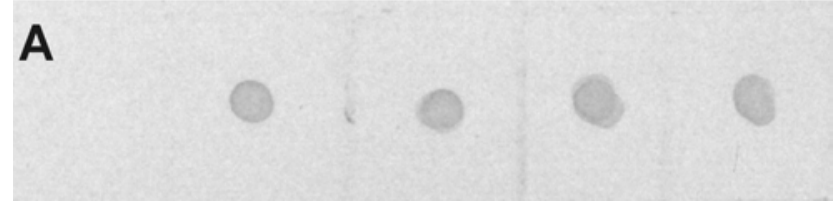

Fig. 4. Binding of plant-derived components (R76 antigen) from nodule cytoplasmic fluid to immobilized bacterial cells. Bacterial suspensions were washed in Tris-buffered saline (TBS) and aliquots $(1 \mu \mathrm{l})$ were dotted on nitrocellulose sheets and blocked with bovine serum albumin $(5 \%$ bovine serum albumin in TBS). Blocked sheets were incubated with cytoplasmic fluid derived from nodule homogenates and immunostained with R76 to reveal the presence of attached antigen. Bacterial strains used were: Rhizobium leguminosarum B659 (lipopolysaccharide-defective mutant) and B551 (exopolysaccharide mutant); Sinorhizobium meliloti EFB1 and 2011; and Escherichia coli DH5 $\alpha$.

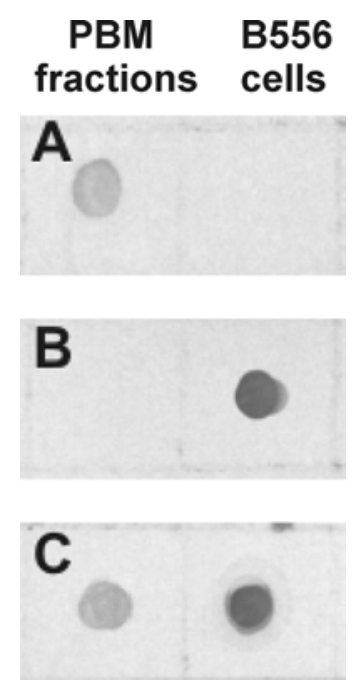

Fig. 5. Binding of Rhizobium leguminosarum B556 cells from free-living culture to immobilized peribacteroid membrane (PBM) derived from nodules containing $R$. leguminosarum 3841 . PBM aliquots $(1 \mu \mathrm{l})$ or Trisbuffered saline (TBS)-washed cells of strain B556 were immobilized on nitrocellulose sheets, blocked with bovine serum albumin $(5 \% \mathrm{BSA}$ in TBS), and probed with A, MAC 206 (anti-PBM-glycolipid antibody) or B, JIM 21 (anti-B556 lipopolysaccharide antibody) as control for loading. C, Replicate sheets were incubated with a suspension of TBS-washed B556 cells and probed with JIM 21 to reveal the presence of B556 cells attached to the immobilized PBM aliquots. 
$6 \mathrm{~A}$ and $\mathrm{B})$. This indicates that the presence of the capsule was masking the outer membrane of Rhizobium spp. from the external probes.

\section{DISCUSSION}

Genetic and cytological approaches have described many cases in which components of the rhizobial cell surface and plant glycoconjugates appear to be involved in nodule development (Kannenberg and Brewin 1994). Symbiotically, defective host Rhizobium cell surface interactions can be due to mutations affecting the bacterial cell surface (Cheng and Walker 1998; Niehaus et al. 1993; Perotto et al. 1994) or they can be due to plant-derived components (Kawaguchi et al. 2002; Romanov et al. 1995; Sherrier et al. 1998; Tikhonovich et al. 1995). Furthermore, when investigating the role or roles of boron in nodule development, we reported previously that boron deficiency affects glycosylation of symbiosomal glycoproteins, and that this was associated with the development of morphologically aberrant symbiosomes (Bolaños et al. 2001). All these reports provide evidence that the $\mathrm{N}_{2}$-fixing endosymbiosis is supported by a physical interaction between the cell surfaces of the interacting partners.

Results presented here indicate that symbiosome development apparently is associated with physical interactions between the cell surface of endophytic bacteria and plant components of the PBF and PBM. These results confirm and extend previous studies suggesting that gaining of the intracellular environment by Rhizobium spp. also is mediated by cell surface interactions (Bolaños et al. 1996). After fractionation of pea nodules and sucrose purification of bacteroids, significant amounts of PBF glycoproteins, including symbiosomal PsNLEC-1A, and PBM glycolipid antigens still were associated closely with the bacteroid fraction (Fig. 1A).

We have demonstrated that the two symbiosomal isoforms of a lectin-like glycoprotein, PSNLEC-1, were able to bind (directly or indirectly) to the cell surface of $R$. leguminosarum 3841 (Figs. 2 and 3). Several bands stained by R76 (Fig. 2A, lane 1, and Fig. 3E) and MAC 254 (Fig. 2B, lane 1) of a $\mathrm{M}_{\mathrm{r}}$ higher than $43 \mathrm{kDa}$, that are common to both PBF and PBM (Perotto et al. 1991) also were detected in binding experiments (Fig. 2A, lane 1) and by R76 antiserum (Fig. 2B, lane 1). Interestingly, the fastest-migrating isoform (PsNLEC-1C) contained in nodule fluid fractions did not bind to the rhizobial cell surface (Fig. 2A, lane 1). Although this isoform is recognized by the antiserum $\mathrm{R} 76$, it is not recognized by the monoclonal antibody MAC 254, suggesting the absence or modification of the $\mathrm{N}$-linked heptasaccharide glycan epitope typical of vacuolar glycoproteins (Faye et al. 1989). In contrast to isoforms PsNLec1A and 1B, which are localized in the symbiosome compartment, PsNLEC-1C apparently is localized in cytoplasmic membrane vesicles and in the vacuole (Dahiya et al. 1997). However, it is not yet clear whether the physical association observed between MAC 254 antigen and fractionated bacterial cells represents a direct molecular association or is the result of an indirect association involving some other symbiosomal component to which PsNLEC is attached.

The role of lectin-like glycoproteins such as PsNLEC-1 is still unclear, although it has been hypothesized that vegetative lectins could serve as a transient store for assimilated nitrogen in nodules (Dahiya and Brewin 2000; Dahiya et al. 1997; VandenBosch et al. 1994). However, several recent studies indicate that PsNLEC-1 may be implicated in symbiosome development and bacteroid maturation. Symbiosomal PsNLEC$1 \mathrm{~A}$ and $1 \mathrm{~B}$ isoforms recognized by MAC 254 and R76 do not appear in nodules from the pea line Sprint-2 Fix $^{-}$(sym31) (Dahiya et al. 1998), a symbiotically defective mutant with altered carbon metabolism (Romanov et al. 1995). Bacteroid development inside nodules of this pea mutant appeared to be arrested at a juvenile stage. Furthermore, in boron-deficient nodules, a carbohydrate epitope modification apparently changes PsNLEC-1 antigenicity so that it is no longer recognized by MAC 254. This apparently is associated with defective targeting of PsNLEC to the symbiosome compartment (Bolaños et al. 2001) and the arrest of bacteroid development at a juvenile stage. In the light of this circumstantial evidence, it is possible to postulate that the symbiosomal isoforms harboring MAC 254 epitope may be involved directly in attachment to the cell surface of endophytic bacteria, perhaps through the mediation of the $\mathrm{N}$-glycan side-chain.

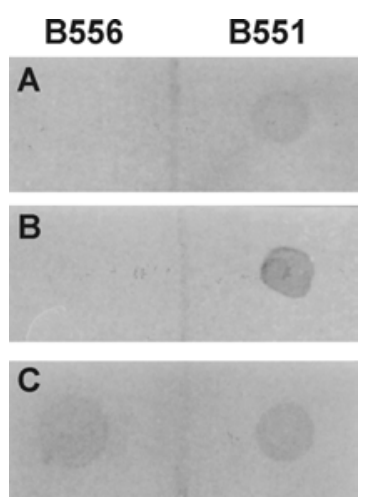

Fig. 6. Effect of the presence of a bacterial capsule on the attachment of components from nodule cytoplasmic fluid and peribacteroid membrane (PBM) components to the surface of free-living rhizobial cells grown as colonies on nitrocellulose sheets on the surface of TY agar plates. Colonies of wild-type strain $R$. leguminosarum B556 and of the mutant derivative B551 lacking extracellular polysaccharide (EPS) were allowed to develop for 3 days following inoculation. Meanwhile, the EPS capsule produced by B556 was immobilized on the nitrocellulose sheets. Sheets were removed from the agar, washed in Tris-buffered saline, blocked in bovine serum albumin, and incubated with fractions containing nodule cytoplasmic fluid. Replicate sheets were A, probed with R76 to reveal attached PsNLEC-1 antigen, $\mathbf{B}$, incubated with PBM fractions and probed with MAC 206 (anti-peribacteroid and -plasma membrane glycolipid), or C, incubated with JIM 21 antibody (anti-B556 and -B551 lipopolysaccharide) as a control for growth of colonies.

Table 2. Rhizobial strains and derivative mutants used in this study

\begin{tabular}{|c|c|c|}
\hline Strain & Derivation or phenotype & Reference \\
\hline \multicolumn{3}{|c|}{ Rhizobium leguminosarum } \\
\hline 3841 & 300 str, biovar viciae, $\mathrm{Fix}^{+}$ & Brewin et al. 1985 \\
\hline B659 & 3841 lps::Tn5, noninvading, Fix ${ }^{-}$ & Rae et al. 1991 \\
\hline B556 & 8002 str containing pRL1JI, nodulates peas, Fix $^{+}$ & Sindhu et al. 1990 \\
\hline B551 & B556 EPS deficient mutant, nonnodulating peas & Borthakur et al. 1986 \\
\hline \multicolumn{3}{|c|}{ Sinorhizobium meliloti } \\
\hline EFB1 & Wild-type $s t r, \mathrm{Fix}^{+}$ & Lloret et al. 1995 \\
\hline 2011 & SU47 str, Fix ${ }^{+}$ & Casse et al. 1979 \\
\hline
\end{tabular}


It was found that these lectin-like glycoprotein antigens became associated with the cell surface of different bacterial strains, including nonrhizobial strains (Fig. 4), the exception being $R$. leguminosarum strain B659, a mutant derivative of strain 3841 with rough colony morphology and a defect in biosynthesis of the core LPS oligosaccharide (Lucas et al. 1996). It was observed previously (Perotto et al. 1994) that LPS-defective Rhizobium mutants showed reduced colonization of pea nodules. Mutants lacking the O-antigen oligosaccharide, like strain B659, were unable to invade nodule cells and tissues. Moreover, when the length of the O-antigen side chain was reduced, rhizobial cells released into host plant cells developed into abnormal symbiosomes, showing defects in bacteroid division and in synchronized division of the PBM. Therefore, it is conceivable that the interaction between PsNLEC-1 glycoproteins (or an associated symbiosomal component) involves contact with the $\mathrm{O}$-antigen polysaccharide LPS of Rhizobium spp.

Bradley and associates (1986) previously have visualized bacterial outer membrane and PBM fragments obtained during fractionation of nodules homogenates in close association with each other. Often, the LPS appeared as a part of a chain-like structure that remains anchored in the peribacteroid membrane fraction. Similarly, nodule-purified bacteroid fractions showed positive staining with MAC 206, an antibody recognizing a glycolipid present in peribacteroid and plasma membranes (Fig. 1B). In contrast, staining of sucrose-purified bacteroid fractions was negative with antibody MAC 207, which recognizes PBM and plasma membrane glycoproteins belonging to the arabinogalactan (AGP) family (Fig. 1C). These results might indicate that glycolipid rafts associated with PBM and enriched for MAC 206 antigen may participate in the direct association between PBM and the cell surface of Rhizobium spp. Glycolipids are commonly implicated in physical associations with the surface of pathogenic bacteria (Karlsson 1989); therefore, this potential interaction could be very important as a signal during the process of endocytosis and for the stability of the symbiosomes in pea nodules.

It has been noted previously that expression of glycolipid antigens recognized by MAC 206 is enhanced at the point of bacterial endocytosis and increases still further in the infected region of pea nodules (Perotto et al. 1991). Similarly, the LPS of $R$. leguminosarum 3841 becomes hydrophobic during bacteroid development, correlating with a changed pattern of reactivity with monoclonal antibodies and an increased capacity for adhesion to hydrocarbons (Kannenberg and Carlson 2001). Consequently, although root uninfected membranes were found to be capable of attaching to bacterial (including LPS or EPS mutants) cell surfaces (data not shown), it is likely that a hydrophobic interaction between the bacterial LPS and the PBM glycolipid becomes stronger during symbiosome development due to enhanced expression of certain PBM glycolipids and to increased hydrophobicity of the bacteroid cell surface.

Robertson and Lyttleton (1984) proposed that a physical association between bacteroid and plant cell surface membranes could be important for the concomitant division of the peribacteroid membrane with intracellular bacteroids in indeterminate nodules, and that variations in the strength of the interaction in different legume species could account for the differences in the number of bacteroids enclosed in a single peribacteroid membrane. Supporting this hypothesis is the fact that PBM-glycolipids recognized by MAC 206 antibody do not express in the infected tissue of determinate Phaseolus nodules (Perotto et al. 1991) that contain symbiosomes enclosing several bacteroids.
Finally, Figure 6 suggests that encapsulated bacteria may be protected from attachment of plant-derived components. The presence of an EPS capsule prevented rhizobial interaction with glycoconjugates secreted into the lumen of the infection thread (Brewin et al. 1994; Rathbun et al. 2002). This is consistent with a protective role of the EPS against a plant-defense response, which could, in part, account for the observed requirement for EPS in successful bacterial infections (Fraysse et al. 2003). Furthermore, the evidence from microscopy indicates that the capsule is reduced or absent from bacterial cells at the point of endocytosis and during bacteroid development. The absence of a capsule would help to promote the physical association between LPS on the bacterial surface and plant-derived membrane and symbiosomal glycoconjugates.

\section{MATERIALS AND METHODS}

\section{Plant growth and inoculation.}

Pea (Pisum sativum cv. Argona) seed were surface sterilized with $70 \%$ (vol/vol) ethanol for $1 \mathrm{~min}$ and $10 \%$ (vol/vol) sodium hypochlorite for $20 \mathrm{~min}$, soaked for $4 \mathrm{~h}$ in sterile distilled water, and then germinated on wet filter paper at $25^{\circ} \mathrm{C}$. After 4 days, seedlings were transferred to plastic growth pots and cultivated on perlite with FP medium for legumes (Fahraeus 1957).

Plants were inoculated with Rhizobium leguminosarum bv. viciae 3841 from an exponential culture in TY medium (Beringer 1974) at approximately $10^{8}$ cells $\mathrm{ml}^{-1}$ and $1 \mathrm{ml} / \mathrm{seed}$ ling and maintained in a growth cabinet at day and night temperatures of 22 and $18^{\circ} \mathrm{C}$, respectively, with a 16- and 8-h photoperiod and an irradiance of $190 \mu \mathrm{mol} \mathrm{m} \mathrm{m}^{-2} \mathrm{~s}^{-1}$. Relative humidity was kept between 60 and $70 \%$.

\section{Fractionation of nodule material.}

Nodules ( $3 \mathrm{~g}$, fresh weight) from pea plants were harvested 3 weeks post inoculation and homogenized at $4^{\circ} \mathrm{C}$ in Tris-DTT buffer (50 mM Tris- $\mathrm{HCl}, \mathrm{pH} 7.5,10 \mathrm{mM}$ dithiothreitol) containing $0.5 \mathrm{M}$ sucrose. The soluble fraction of the homogenate (the cytoplasmic supernatant) was collected by filtration through Miracloth and centrifuged for $30 \mathrm{~min}$ at $100,000 \times g$ to remove debris, including the symbiosome and bacteroid fractions. Bacteroids still enclosed by peribacteroid membrane were prepared by fractionation and then were purified by centrifugation through a sucrose gradient as described by Brewin and associates (1985). The peribacteroid membrane fraction then was obtained according to Perotto and associates (1991). To avoid loses of glycoproteins, all of the soluble fractions derived from the supernatants obtained during fractionation were collected together and centrifuged for $30 \mathrm{~min}$ at $100,000 \times \mathrm{g}$. The resulting supernatant, which included cytoplasmic PsNLEC-1C and isoforms -1A and -1B released from symbisomes, was used to study the binding activity of those glycoproteins.

\section{Bacterial strains.}

The strains of rhizobia used are listed in Table 2. Rhizobial strains and derivative mutants were grown on complete TY medium (Difco Laboratories, Detroit) (Beringer 1974). Bacteria different from Rhizobium spp. (for example, E. coli strain DH5 $\alpha$ [BRL Inc., Gaithersburg, MD, U.S.A.]) were grown on LB agar medium. When required, bacteria were grown on sterilized nitrocellulose sheets on the surface of TY agar plates.

\section{Antibodies and antisera.}

Rat monoclonal antibodies and rabbit antisera used in this study are listed in Table 1 . MAC 254 reacts with carbohydrate epitopes associated with glycoproteins that are targeted to the 
peribacteroid fluid and membrane (Perotto et al. 1991), including two nodule-specific lectin-like glycoproteins (PsNLEC$1 \mathrm{~A}$ and $-1 \mathrm{~B}$ ) of approximately 30 - and $27 \mathrm{kDa}$ (Kardailsky et al. 1996) that are localized in the peribacteroid fluid of pea nodules symbiosomes (Dahiya et al. 1997). Rabbit antiserum R76, reacting with PsNLEC-1, was prepared from antigenic material obtained by heterologous expression of the PsNlecl cDNA cloned in E. coli, as described by Dahiya and associates (1997). The antiserum was precipitated routinely with E. coli lysate to remove cross-reacting antibodies. MAC 206 was used to identify glycolipid epitopes carried by the glycocalyx of both peribacteroid and host cell plasma membrane, while MAC 207 recognized carbohydrate components on glycoproteins $\left(\mathrm{M}_{\mathrm{R}} 45\right.$ to $\left.120 \mathrm{kDa}\right)$ associated with peribacteroid and cell plasma membranes (Perotto et al. 1991). MAC 57 recognizes a constitutive epitope associated with the LPS-1 component (O-antigen) of strains 3841 (Brewin et al. 1986) and B556 (Sindhu et al. 1990). JIM 21 recognizes an epitope on the LPS-1 of strain B556 (Sindhu et al. 1990).

\section{In vitro binding experiments and immunoassays.}

Prior to being used in binding experiments, rhizobia were grown in TY agar media for $48 \mathrm{~h}$ at $28^{\circ} \mathrm{C}$, and E. coli DH5ain $\mathrm{LB}$ agar for $24 \mathrm{~h}$ at $37^{\circ} \mathrm{C}$. Cells were washed three times in TBS and resuspended in a convenient incubation buffer at 1.0 optical density units $(600 \mathrm{~nm})$. For binding experiments, aliquots of nodule-derived cytoplasmic fluid (50 $\mu \mathrm{l}$, containing approximately $0.5 \mu \mathrm{g}$ of protein) were incubated for $1 \mathrm{~h}$ at $4^{\circ} \mathrm{C}$ with $10 \mu \mathrm{l}$ of bacterial suspensions. After incubation, the mixture was centrifuged for $1 \mathrm{~min}$ at $10,000 \times g$. The resulting pellets were washed three times in TBS, boiled in Laemmli buffer containing $10 \%$ SDS, and the solubilized material was separated following SDS-PAGE (Laemmli 1970) with 12\% (wt/vol) polyacrylamide separating gels. Gels were electroblotted to nitrocellulose sheets (Bittner et al. 1980) and probed with R76 antiserum or MAC 254 monoclonal antibody at a final concentration of $1 / 2,000(\mathrm{vol} / \mathrm{vol})$ and $1 / 100(\mathrm{vol} / \mathrm{vol})$ respectively. Immunostaining was visualized using a goat antirabbit immunoglobulin $\mathrm{G}$ (IgG) (for antiserum) or a goat antirat IgG (for monoclonal antibodies) secondary antibody conjugated to peroxidase (Bradley et al. 1988).

Alternatively, aliquots $(1 \mu \mathrm{l})$ of TBS-washed cells were immobilized on nitrocellulose sheets. Sheets were blocked for $1 \mathrm{~h}$ with $5 \%$ bovine serum albumin (BSA) in TBS and then incubated $\left(1 \mathrm{~h}\right.$ at $\left.4^{\circ} \mathrm{C}\right)$ with samples of nodule cytoplasmic fluid at a final concentration of protein at $5 \mu \mathrm{g} \mathrm{m}{ }^{-1}$. After incubation, sheets were blocked again and binding activity was detected by R76 or MAC 254 immunostaining and anti-rat IgG secondary antibody conjugated to peroxidase.

For monitoring binding of PBM to bacterial cells, BSAblocked nitrocellulose sheets with immobilized bacteria were incubated $\left(1 \mathrm{~h}\right.$ at $\left.4^{\circ} \mathrm{C}\right)$ with plant membrane fractions (at a final concentration of protein at approximately $5 \mu \mathrm{g} \mathrm{ml} \mathrm{m}^{-1}$ ). After incubation, blots were blocked again with BSA and binding was monitored by using antibodies MAC206 (antiPBM and anti-cell membrane glycolipid) or MAC207 (antiPBM and anti-cell membrane glycoproteins) and revealed with anti-rat IgG secondary antibody conjugated to peroxidase.

\section{ACKNOWLEDGMENTS}

This work was supported by MCYT no. BOS2002-04164-CO3-02.

\section{LITERATURE CITED}

Ampe, F., Kiss, E., Sabourdy, F., and Batut, J. 2003. Transcriptome analysis of Sinorhizobium meliloti during symbiosis. Genome Biol. 4:R15.
Beringer, J. E. 1974. R factor transfer in Rhizobium leguminosarum. J. Gen. Microbiol. 84:188-198.

Bittner, M., Kupferer, P., and Morris C. F. 1980. Electrophoretic transfer of proteins and nucleic acids from the slab gels to diazobenzyloxymethyl cellulose or nitrocellulose sheets. Anal. Biochem. 102:459-471.

Bolaños, L., Brewin, N. J., and Bonilla, I. 1996. Effects of boron on Rhizobium-legume cell surface interactions and nodule development. Plant Physiol. 110:1249-1256.

Bolaños, L., Cebrián, A., Redondo-Nieto, M., Rivilla, R., and Bonilla, I 2001. Lectin-like glycoprotein PsNLEC-1 is not correctly glycosylated and targeted in boron-deficient pea nodules. Mol. Plant-Microbe Interact. 14:663-670.

Borthakur, D., Barber, C. E., Lamb, J. W., Daniels, J. A., Downie, J. A. and Johnston, A. W. B. 1986. A mutation that blocks exopolysaccharide synthesis prevents nodulation of peas by Rhizobium leguminosarum but not of beans by Rhizobium phaseoli. Mol. Gen. Genet. 203:320-323.

Bradley, D. J., Butcher, G. W., Galfre, G., Wood E. A., and Brewin, N. J. 1986. Physical association between the peribacteroid membrane and lipopolysaccharide from the bacteroid outer membrane in Rhizobiuminfected pea root nodule cells. J. Cell Sci. 85:47-61.

Bradley, D. J., Wood, E. A., Larkins, A. P., Galfre, G., Buchter, G. W., and Brewin, N. J. 1988. Isolation of antibodies reacting with peribacteroid membranes and other components of pea root nodules containing Rhizobium leguminosarum. Planta 173:149-160.

Brewin, N. J. 1991. Development of the legume root nodule. Annu. Rev. Cell. Biol. 7:191-226.

Brewin, N. J., Bolaños, L., Dahiya, P., Gardner, C. D., Hernández, L. E., Kardailsky, I. V., Rathbun, E. A., and Sherrier, D. J. 1995. Differentiation of the symbiosome compartment in pea nodule cells. Pages 455-460 in: Nitrogen Fixation: Fundamentals and Applications. I. A. Tikhonovich, N. A. Provorov, V. E. Romanov, and W. E. Newton, eds. Kluwer, Dordrecht, The Netherlands.

Brewin, N. J., Rae, A. L., Perotto, S., Kannenberg, E. L., Rathbun, E. A., Lucas, M. M., Gunder, A., Bolaños L, Kardailsky, I. V., Wilson K. E., Firmin J. L., and Downie J. A. 1994. Bacterial and plant glycoconjugates at the Rhizobium-legume interface. Pages 61-73 in: Molecular Botany: Signals and the Environment. D. J. Bowles, P. M. Gilmartin, J. P. Knox, and G. G. Lunt, eds. Portland Press, London.

Brewin, N. J., Robertson, J. G., Wood, E. A., Wells, B. A., Larkins, A. P., Galfre, G., and Butcher, G. W. 1985. Monoclonal antibodies to antigens in the peribacteroid membrane from Rhizobium-induced root nodules of pea-cross-react with plasma membrane and Golgi bodies. EMBO (Eur. Mol. Biol. Organ.) J. 4:605-611.

Brewin, N. J., Wood, E. A., Larkins, A. P., Galfre, G., and Butcher, G. W. 1986. Analysis of lipopolysaccharides of Rhizobium leguminosarum using monoclonal antibodies. J. Gen. Microbiol. 132:1959-1966.

Casse, F., Boucher, C., Julliot, J. S., Michel, M., and Dénarie, J. 1979. Identification and characterization of large plasmids in Rhizobium meliloti using agarose gel electrophoresis. J. Bacteriol. 113:229-242.

Cheng, H. P., and Walker, G. C. 1998. Succinoglycan is required for initiation and elongation of infection threads during nodulation of alfalfa by Rhizobium meliloti. J. Bacteriol. 180:5183-5191.

Dahiya, P., and Brewin, N. J. 2000. Immunogold localisation of callose and other cell wall components in pea nodule transfer cells. Protoplasma 214:210-218.

Dahiya, P., Kardailsky, I. V., and Brewin, N. J. 1997. Immunolocalization of PsNLEC-1, a lectin-like glycoprotein expressed in developing pea nodules. Plant. Physiol. 115:1431-1442.

Dahiya, P., Sherrier, D. J., Kardailsky, I. V., Borisov, A. Y., and Brewin, N. J. 1998. Symbiotic gene sym31 controls the presence of a lectinlike glycoprotein in the symbiosome compartment of nitrogen-fixing pea nodules. Mol. Plant-Microbe Interact. 11:915-923.

Day, D. A., and Udvardi, M. K. 1993. Metabolite exchange across symbiosome membranes. Symbiosis 14:175-189.

Dénarié, J., and Cullimore, I. 1993. Lipo-oligosaccharide nodulation factors: a new class of signaling molecules mediating recognition and morphogenesis. Cell 74:951-954.

Fahraeus, G. 1957. The infection of clover root hairs by nodule bacteria studied by a simple glass technique. J. Gen. Microbiol. 16:374-381.

Faye, L., Johnson, K. D., Storm, A., and Chrispeels, M. J. 1989. Structure, biosynthesis and function of asparagine-linked glycans on plant glycoproteins. Physiol. Plant. 75:309-314.

Fraysse, N., Couderc, F., and Poinsot, V. 2003. Surface polysaccharide involvement in establishing the Rhizobium-legume symbiosis. Eur. J. Biochem. 270:1365-1380.

Gage, D. J., Bobo, T, and Long, S. R. 1996. Use of green fluorescent protein to visualize the early events of symbiosis between Rhizobium meliloti and alfalfa (Medicago sativa). J. Bacteriol. 178:7159-7166.

Kannenberg, E. L., and Brewin, N. J. 1994. Molecular mechanisms of host plant invasion by Rhizobium. Trends Microbiol. 2:277-283. 
Kannenberg E. L., and Carlson, R. W. 2001. Lipid A and O-chain modifications cause Rhizobium lipopolysaccharides to become hydrophobic during bacteroid development. Mol. Microbiol. 39(2):379-391.

Kardailsky, I. V., Sherrier, D. J., and Brewin, N. J. 1996. Identification of a new pea gene, PsNlec1, encoding a lectin-like glycoprotein isolated form the symbiosomes of root nodules. Plant. Physiol. 111:49-60.

Karlsson, K. A. 1989. Animal glycosphingolipids as membrane attachment sites for bacteria. Annu. Rev. Biochem. 58:309-350.

Kawaguchi, K., Imaizumi-Anraku, H., Koiwa, H., Niwa, S., Ikuta, A., Syono, K., and Akao, S. 2002. Root, root hair, and symbiotic mutants of the model legume Lotus japonicus. Mol. Plant-Microbe Interact. 15:17-26.

Knox, J. P., Linstead, P. J., Peart, J, Cooper, C., and Roberts, K. 1991 Developmentally regulated epitopes of cell surface arabinogalactan proteins and their relation to root tissue pattern formation. Plant $\mathrm{J}$. 1:317-326.

Laemmli, U. K. 1970. Cleavage of structural proteins during the assembly of the head of bacteriophage T4. Nature 227:680-685.

Lloret, J., Bolaños, L., Lucas, M. M., Peart, J. L., Brewin, N. J., Bonilla, I., and Rivilla, R. 1995. Different alterations are induced by ionic and osmotic stress in the lipopolysaccharide of a strain of Rhizobium meliloti. Appl. Environ. Microbiol. 61:3701-3704.

Long, S. R. 1989. Rhizobium-legume nodulation: Life together in the underground. Cell 56:203-214.

Lucas, M. M., Peart, J. L., Brewin, N. J., and Kannenberg, E. L. 1996. Isolation of monoclonal antibodies reacting with a core component of lipopolysaccharide from Rhizobium leguminosarum strain 3841 an mutant derivatives. J. Bacteriol. 178:2727-2733.

Mellor, R. B. 1989. Bacteroids in the Rhizobium-legume symbiosis inhabit a plant internal lytic compartment: Implications for other microbial endosymbioses. J. Exp. Bot. 40:831-839.

Miao, G. H., Hong, Z., and Verma, D. P. S. 1992. Topology and phosphorylation of soybean nodulin-26, an intrinsic protein of the peribacteroid membrane. J. Cell. Biol. 118:481-490.

Niehaus, K., Kapp, D., and Pühler, A. 1993. Plant defense and delayed infection of alfalfa pseudonodules induced by an exopolysaccharide (EPS I)-deficient Rhizobium meliloti mutant. Planta 109:415-425.

Parniske, M. 2000. Intracellular accommodation of microbes by plants: a common developmental program for symbiosis and disease? Curr. Opin. Plant Biol. 3:320-328.

Perotto, S., Brewin N. J., and Kannenberg, E. L. 1994. Cytological evidence for a host defense response that reduces cell and tissue invasion in pea nodules by lipopolysaccharide-defective mutants of Rhizobium leguminosarum strain 3841. Mol. Plant-Microbe Interact. 7:99-112.
Perotto, S., Donovan, N., Drobak, B. J., and Brewin, N. J. 1995. Differentia expression of a glycosyl inositol phospholipid antigen on the peribacteroid membrane during pea nodule development. Mol. Plant-Microbe Interact. 8:560-568.

Perotto, S., VandenBosch, K. A., Butcher, G. W., and Brewin, N. J. 1991. Molecular composition and development of the plant glycocalyx associated with the peribacteroid membrane of pea root nodules. Development 112:763-773.

Rae, A. L., Perotto, S., Knox, J. P., Kannenberg, E. L., and Brewin, N. J. 1991 Expression of extracellular glycoproteins in the uninfected cells of developing pea nodule tissue. Mol. Plant-Microbe Interact. 4:563-570.

Rathbun, E. A., Naldrett, M. J., and Brewin, N. J. 2002. Identification of a family of extension-like glycoproteins in the lumen of Rhizobiuminduced infection threads in pea root nodules. Mol. Plant-Microbe Interact. 15:350-359.

Robertson, J. G., and Lyttleton, P. 1984. Division of peribacteroid membranes in root nodules of white clover. J. Cell. Sci. 69:147-157.

Romanov, V. I., Gordon, A. J., Minchin, F. R., Witty, J. F., Skot, L., James, C. L., Borisov, A. Y., and Tikhonovich, I. A. 1995. Anatomy, physiology and biochemistry of root nodules of Sprint-2Fix(-), a symbiotically defective mutant of pea (Pisum sativum L.). J. Exp. Bot. 46:1809-1816.

Sherrier, D. J., Borisov, A. Y., Tikhonovich, I. A., and Brewin, N. J. 1997. Immunocytological evidence for abnormal symbiosome development in nodules of the pea mutant line Sprint $2 \mathrm{Fix}^{-}$(sym31). Protoplasma 199:57-68.

Sindhu, S. S., Brewin, N. J., and Kannenberg E. L. 1990. Immuno-chemical analysis of lipopolysaccharides from free-living and endo-symbiotic forms of Rhizobium leguminosarum. J. Bacteriol. 172:1804-1813.

Tikhonovich, I. A., Borisov, A. Y., Chvabauskene, I. A., Kamardin, N. N., Kravchenko, L. V., Lebsky, V. K., Minchin, F., Morzhina, E. V., Romanov, V. I., Skot, L., Tchetkova, S. A., and Tsyganov, V. E. 1995. Plant genetical control at the crucial steps of symbiosis. Pages 461-466 in: Nitrogen Fixation: Fundamentals and Applications. I. A. Tikhonovich, N. A Provorov, V. E. Romanov, and W. E. Newton, eds. Kluwer, Dordrecht, The Netherlands.

VandenBosch, K. A., Rodgers, L. R., Sherrier, D. J., and Kishinevsky, B. D. 1994. A peanut nodule lectin in infected cells and in vacuoles and the extracellular matrix of nodule parenchyma. Plant Physiol. 104:327-337.

Vincent, J. L., and Brewin, N. J. 2000. Immunolocalisation of a cysteine protease in vacuoles, vesicles and symbiosomes of pea nodule cells. Plant Physiol. 123:521-530.

Vincent, J. L., Knox, M. R., Ellis, T. H. N., Kalo, P., Kiss, G. B., and Brewin, N. J. 2000. Nodule-expressed Cyp15a cysteine protease genes map to syntenic genomic regions in Pisum and Medicago spp. Mol. Plant-Microbe Interact. 13:715-72 